\title{
Biogeographical Distribution Model of Flowering Plant Capparis micracantha Using Support Vector Machine (SVM) and Generalized Linear Model (GLM) and its Ex-situ Conservation Efforts
}

\author{
Inggit Puji Astuti a, ${ }^{\text {, }}$, Angga Yudaputra ${ }^{\text {a }}$, Dipta Sumeru Rinandio ${ }^{\text {a }}$, Ade Yusuf Yuswandi ${ }^{\text {a }}$ \\ ${ }^{a}$ Research Center for Plant Conservation and Botanic Gardens, Indonesian Institute of Sciences, Bogor 16211, West Java, Indonesia. \\ Corresponding author: ${ }^{*}$ inggit.pa@gmail.com
}

\begin{abstract}
Capparis micracantha is a flowering plant species with a wide range of distributions. It is often used as traditional medicine by local people. This species is often overlooked due to very limited information that reveals about its conservation aspects. This study aims to update the distribution records and predict the potential current distribution of this species. Some new occurrence records were obtained through a direct field survey, plant inventory database, and reliable scientific papers. In order to gain more information about current distribution, Species Distribution Modelling (SDM) was applied to predict the potential current distribution of this species in Indonesia. Two algorithms of machine learning (SVM and GLM) were applied to produce predictive distribution maps. The models were built from occurrence records data and environmental variables (climate and topography). Area Under Curve (AUC) was used to evaluate the model prediction. The AUC value of those models $>0.80$ means those models have a good performance. The AUC value of those models is stated in SVM (0.86) and GLM (0.824). SVM and GLM have almost similar resulting predictive maps of current distribution. The predictive maps would be useful to give information about the regions in Indonesia that have similar environment characteristics and climate conditions where the species are observably present. This species has also been conserved through ex-situ conservation strategies, but the seedling growth of this species still remains a challenge.
\end{abstract}

Keywords - Biogeographical distribution; Capparis micracantha; Ex-situ conservation; GLM; SVM.

\section{INTRODUCTION}

Capparis is a genus of Capparaceae. This genus is estimated to have 250 species and is widely distributed in tropic and subtropics. Capparis micracantha is one of the plant species that belongs to Capparaceae [1]. There are several synonyms of Capparis micracantha including Capparis billardieri DC; Capparis callosa Blume; Capparis conpicua Wall; Capparis odorata Blanco; Capparis forsteniana Miq; Capparis roydsiifolia Kurz; Capparis hainanensis Oliv; Capparis myrioneura Hallier.f .; Capparis bariensis Pierre ex Gagnep; Capparis donnaiensis Pierre ex Gagnep; Capparis venosa Merr; Capparis liangii Merr \& Chun and Capparis petelotii Merr. The local names of this species are Balung, Kledung (Java), and Ketket Kayu Joh (Bali) [2]. It has a relatively wide distribution that stretches from Burma, Yunan, Hainan, Thailand, Vietnam, Malay Peninsula, Philippines, Northern Borneo, Sulawesi, Halmahera, East Nusa Tenggara, Java, and South Sumatra
[2]-[4]. Another report states that this species is also seen in Central Java, East Java, and Madura and rarely in West Java. It is commonly found in tropical rain forests, teak forests, evergreen forests, dry areas (calcareous soilsa and savanna), roadsides, coastal areas, and mostly in lowland areas with an altitude up to $1400 \mathrm{~m}$ above sea level [5]. It is also recorded in Nglanggeran, Gunung Kidul [6]. This area has a tropical monsoon climate (Am) climatic characteristic based on Köppen's climate classification [7], [8]. The characteristics of a tropical monsoon climate are the minimum temperature around $18{ }^{\circ} \mathrm{C}$ and monthly averaged minimum precipitation $\leq$ $60 \mathrm{~mm}$, which is $4 \%$ higher than annual averaged precipitation [9]. The wide range of C. micracantha distribution indicates that it has high adaptability to various gradients of environment.

It is used as a medicinal herbal; its parts are used as medicinal ingredients such as the root and bark of its stem. The bark of C.micracantha is used as an anti-inflammatory drug, relieving hot pain symptoms, fever and bruises [10]. A red to purple fruit has a sweet aromatic flavour, but it is unsafe 
to eat when unripe [10]. In addition, the root is used as a diuretic, stomachic, antipyretic [11], and tonic [12]. In Thailand and the Philippines, its root is also used for traditional medicine for diabetes mellitus [13]. The wood is used for treating biliousness, stomachache, and giddiness. The bark is used as a diuretic to treat bronchitis and nasal ulcerations. The stem is used in the treatment of breast cancer [10]. The stem is crushed with water and applied topically to relieve pain and swelling [12]. In Thailand, this species is used as raw material for herbal medicine, namely Ha-Rak. A previous study about Ha-Rak stated that herbal medicinal properties in the form of lupeol have anticancer activity [14]. Furthermore, Ha-Rak has functional uses for preventing and delaying skin photoaging through restoring redox homeostasis [15].

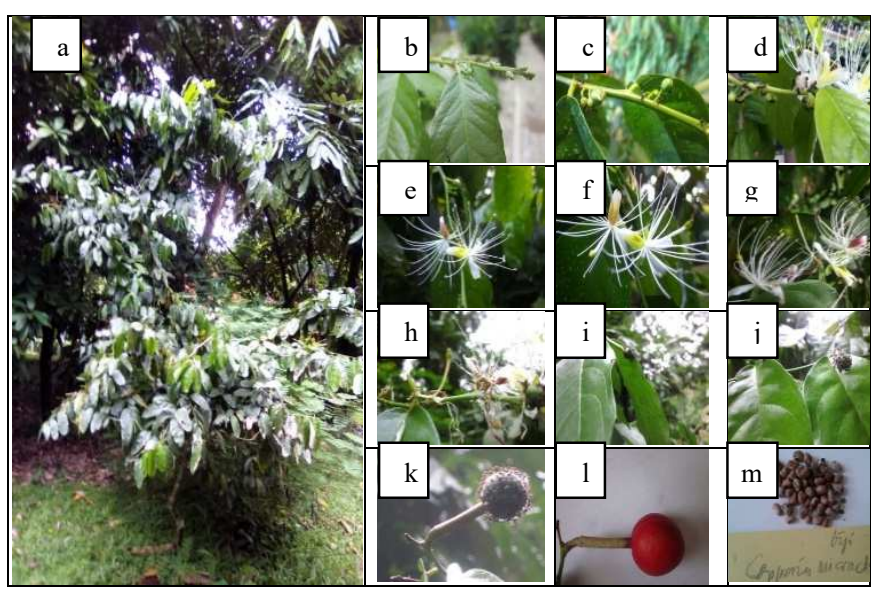

Fig. 1 Capparis micracantha, tree (a); development of leaves to flower buds (b-d); blooming flowers (e-g); development of prospective fruits $(\mathrm{h}-\mathrm{j}$ ); young fruit, ripe fruit $\&$ seeds $(\mathrm{k}-\mathrm{m})$.

According to the records, the locations where this species is present are affected by the natural disaster (Tsunami), such as Panaitan Island, Ujung Kulon (West Java), North coast of Bondowoso (East Java), Palu, Donggala, and Parigi (Central Sulawesi. Furthermore, some habitats in Gorontalo and Bali are threatened by land-use change. Anthropogenic disturbances are also threatening biodiversity in recent times [16], [17]. Although C.micracantha is not included on the list of threatened plants and the IUCN Red List has published no global assessment, an effort for updating information about the current distribution of this species would be important since the first conservation effort was started at Teijsmann period around 1873 - 1876 in the Bogor Botanic Gardens. No information about the existence of this species in Bogor Botanic Gardens after that period. The current information that has been stated by Kew Webb, the distribution of C.micracantha is scattered in Sumatra, Java, Kalimantan, Sulawesi, Bali, West Nusa Tenggara, East Nusa Tenggara, Maluku Islands and Papua. Another piece of information provided in Jacobs's report is that the distribution records data of C. micracantha in Indonesia is too long (55 years ago). However, Jacobs's report is very important as a basic guideline for this investigation. By conserving this species through ex-situ, the opportunity to study many aspects of $C$. micracantha for conservation purposes becomes more accessible and easier.
This study aims to update the distribution records based on the current direct field survey, plant inventory databases, scientific journals, and herbarium databases. That presence records data will be used to predict the potential current distribution of $C$. micracantha in unsurveyed locations. It is impossible to survey all regions to obtain the distribution data of this species due to financial limitations and time restrictions. In order to understand the potential distribution of this species in unsurveyed locations, the modeling distribution can be considered as an alternative way. Species distribution modeling (SDM) is now widely used to model and predict the potential distribution of biodiversity in response to global change. It is also an important approach for conservation endeavors [18], [19]. SDM is also used to understand the species response to environmental change [20]. Recent studies stated that SDM was used for many conservation purposes, such as predicting Egyptians medicinal plants distribution [21], predicting the potential distribution of endemic plant Rosa Arabica [22], understanding the impact of climate change on the distribution Paeonia ostii across china [23], and assessing the cultivation areas of Scutellaria baicalensis in China [24]. SDM incorporates the occurrence records and abiotic factors such as topography, climate, and land-use change [25], [26].

For finding a reliable predictive current distribution map, machine learning algorithms are widely used to address the impact of climate dynamics on biodiversity distribution. Some algorithms are well tested to predict the current distribution of Guetarda speciosa [27]. Furthermore, those algorithms are also applied to predict the potential distribution of invasive species Caliandra calothyrsus in Bali [28]. SVM (Support Vector Machine) is a machine learning algorithm that belongs to a family of generalized linear classifiers. The basis work of SVM is a discriminative classifier defined by a separating hyperplane (the line divides a plane into two different parts of class). SVM, an algorithm of machine learning, is commonly used as a tool for classification. It produces high accuracy and reproducibility performance [29]. SVM is recently used to estimate the species range of parapatric species [30]. Support Vector Machine (SVM) is one of the machine learning algorithms that outperformed the prediction of Eusideroxylon zwageri with AUC value $>0.80$ and TSS value (0.74) [31]. In addition, SVM showed an outstanding performance in predicting habitat suitability of Morina persica L. [32].

GLM is often used to determine the distribution pattern of species [33] [34]. GLM is also considered a proper tool for agricultural activities and environmental protection [35]. In a previous study, GLM and MaxEnt were used to understand the effect of grain size on the predicted distribution area [36]. The predictive current distribution map would be useful to provide information about other regions that are suitable for this species. By understanding the predictive potential of current distribution, the conservation strategies of this species become more efficient and effective. This study also provides brief information about the conservation efforts of this species in Bogor Botanic Gardens, including seeds germination, seedling growth, flowering, and fruiting aspects. 


\section{MATERIALS AND METHODS}

\section{A. Study Species}

Erect shrub-shaped plant and slightly bent, 1 - $6 \mathrm{~m}$ high, greyish-green stems, thorns, branching appears not far from the ground. Single leaf, oval, leaf $6-25 \mathrm{~cm}$ in length, leaf width around 3-10 cm, rounded leaf tip, flat-leaf edge, pointed leaf base, shiny green upper leaf blade, whitish-green lower leaf blade, short petiole brownish green. Single flowers, appearing in branches, near the axillary leaves lined $4-6$ flowers, rounded flower buds, green petals, white flower crowns, when blooming one flower crown with yellow or purple spots on the bottom of the flower crown, many stamens (16-25), green pistil 1, white pistil (many rudimentary pistils). Buni fruit, round to oval shape, green when young, red when ripe, and contains many seeds wrapped in aryl between the seeds, kidney-shaped seeds, grayish-brown - blackish brown.

\section{B. Species Distribution Modelling}

The occurrence records of Capparis micracantha were derived from direct field survey, plant inventory database, herbarium database, and reliable scientific papers. The direct field survey was conducted in several islands of Indonesia. It has been taken around two years of data collection. There are 129 occurrence records of $C$. micracantha were recorded on this study. Seven bioclimatic variables and elevation data were used as a predictor of the model. The bioclimatic variables were extracted from the global climate database (https://www.worldclim.org/; [37]. These bioclimatic variables were Annual Mean Temperature, Isothermality, Temperature Seasonality, Annual Precipitation, Precipitation of Wettest Month, Precipitation of Driest Month, Precipitation Seasonality (Coefficient of Variation). Bioclimatic variables were derived from the monthly temperature and rainfall values to generate more biologically meaningful variables. The elevation data of Indonesia was derived from SRTM Elevation data. Both bioclimatic and elevation data are available at 2.5 minutes spatial resolution (approximately $5 \mathrm{~km}$ grid cell sizes at the equator) [38].

Two machine learning algorithms were used to predict the potential current distribution of $C$. micracantha in Indonesia. Support Vector Machine (SVM) and Generalized Linear Model (GLM) were selected based on their performances in predicting the distribution model in several previous studies. A package "dismo" was used as a method for species distribution modelling [39]. Both presence and absence (pseudo-absence) occurrence records were used as input of the models. The 200 random points of pseudo absence data were chosen to represent the absence occurrence records of $C$. micracantha in Indonesia. The data was then split into training data and testing data with the proportion of $75 \%: 25 \%$ ( using $4 \mathrm{k}$-fold data partition). The Area Under Curve (AUC) was used to evaluate the model prediction performance. The output of those two models is predictive current distribution maps of $C$. micracantha in Indonesia.

\section{Ex-situ Conservation Efforts}

The multi propagation of this species has been conducted by germinating the seeds in growing media (sand). The seeds were derived from a plant living collection that has been producing fruits. The germination process and seedling growth observation were conducted in the plant nursery building IX of Bogor Botanic Gardens. The flowering and fruiting process observation has been conducted toward several plant living collections.

\section{RESULT AND DISCUSSION}

The principal reason for using several bioclimatic variables instead of all bioclimatic variables is to take some of those relevant to Indonesia. Bioclimatic variables and elevation are chosen as the model's inputs because the study area covers quite a large region of Indonesia. In order to understand the environmental factors that affect the distribution of plant distribution, some environmental factors such as land use, soil type, and biotic interaction can be excluded if the study area belongs to a regional scale domain $(200-2000 \mathrm{~km})$. Even though dispersal history and spatial barriers are also considered important factors [40], these can also be excluded if the study scale is relatively wide.

Both algorithms of machine learning have the Area Under Curve (AUC) value $>0.80$, which indicates both models are categorized into good models in predicting the potential current distribution of $C$. micracantha. The classification of the model based on the AUC Value is stated as the following: model with AUC in range 0.9-1 (excellent), 0.8-0.9 (good), 0.7-0.8 (fair), 0.6-0.7 (poor), and 0.5-0.6 (fail) [41]. The area under the curve (AUC) is a perfect performance metric for ROC curve. The higher the AUC value, the better performance of the model. SVM model has an AUC value of 0.86, while GLM has AUC value of 0.824. Those models distinguish between the presence and absence of the resulting predictive maps. According to the direct field survey and other sources, the occurrence records of this species are most likely centered in Java Island and scattered to some islands such as Sumatra, Kalimantan, Sulawesi, and Bali. According to the presence points, most of this species is found in areas close to the sea (coastal areas) and small islands, and some of them are found far away from the coastal.

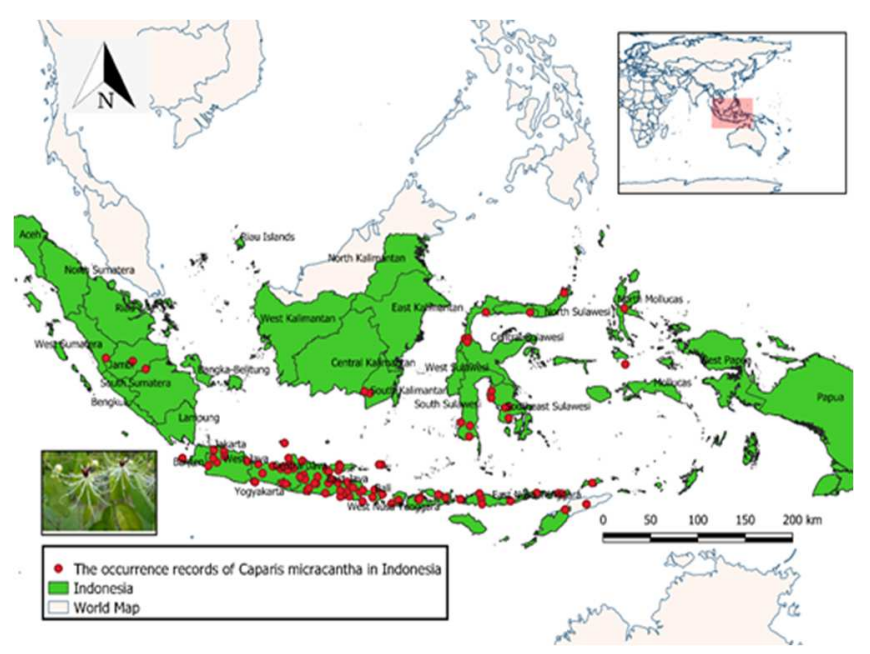

Fig. 2 The occurrence records of Capparis micracantha that are collected from direct field survey, plant inventory database, herbarium specimen and other sources (scientific journals and reports). 


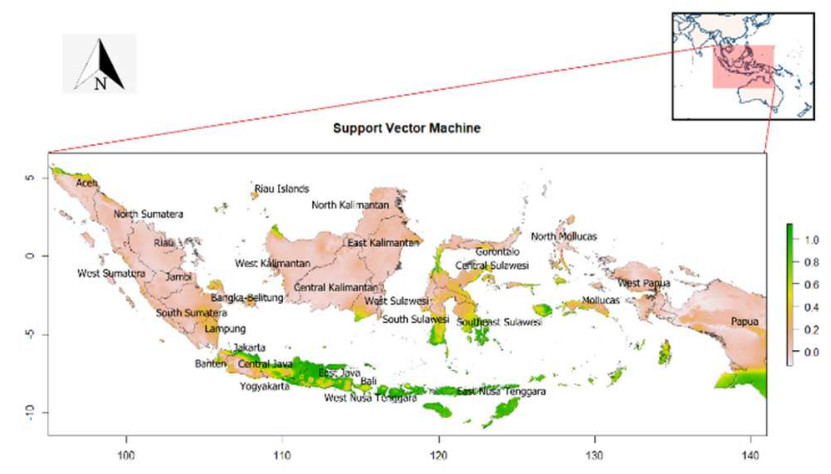

Fig. 3 Predictive map of current potential distribution of Capparis micracantha using Support Vector Machine (SVM).

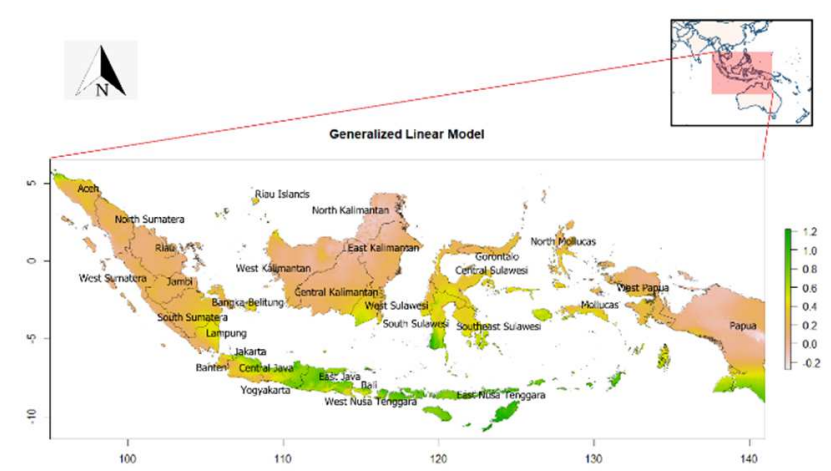

Fig. 4 Predictive map of current potential distribution of Capparis micracantha using Generalized Linear Model (GLM).

A different color ramp represents the predictive maps on the map. The darker green color represents the region's best predicted as the distribution of $C$. micracantha. While the color of pink indicates the area that less suitable for the distribution of $C$. micracantha. Support Vector Machine (SVM) algorithm predicts almost regions in Java, Bali, West Nusa Tenggara, East Nusa Tenggara, Aceh, West Kalimantan, South Kalimantan, Central Sulawesi, South Sulawesi, Southeast Sulawesi, Moluccas, and Southern part of Papua as the high suitable area for the distribution of C. micracantha based on bioclimatic variables and elevation. Another region indicates the area that less suitable for the distribution of C.micracantha. Generalized Linear Model (GLM) predicts almost regions in Java, Bali, West and East Nusa Tenggara, Northern part of Aceh, Lampung, South Sumatra, South Sumatra, South Sulawesi, West Sulawesi, Southeast Sulawesi, Moluccas, and Southern part of Papua. Although SVM and GLM are not precisely predicting the same all regions regarding the distribution of $C$. micracantha on the predictive map, some regions are similarly predicted on the distribution maps from both SVM and GLM. These algorithms predict another region compared to the observation records. These algorithms predict some parts of Aceh, West Kalimantan, Moluccas, and Southern Papua. The predictive maps most likely show the coastal area as the suitable predicted habitat of this species. It is similar to the location where the species found based on the observation data. Java is predicted as the distribution center for C.micracantha from both two models. The predictive map of Java shows that the distribution area of this species is not only in coastal area but also in other areas throughout Java. The predictive map of potential current distribution shows another region with similar environmental characteristics to the location where the species are found.

Predictive maps that are resulted from this study could give general information about the potential distribution of this species based on bioclimatic variables and topography only. The real distribution may be different from the predictive maps because some variables that are not being considered may affect the distribution. Some species are probably tolerant of climatic variation and resist the habitat change where they are initially found. Using two types of algorithms is to convince that the resulting predictive maps are relevant and robust. Those two predictive maps could be compared in terms of predicted locations of potential distribution.

\section{Ex-situ conservation strategies.}

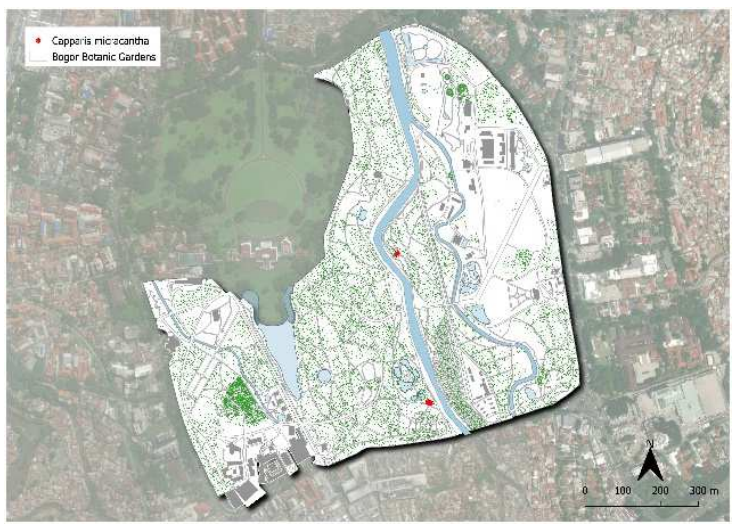

Fig. 5 The occurrence points of Capparis micracantha in Bogor Botanic Gardens.

The genus Capparis has been conserved in Bogor Botanic Garden. Several conservation programs in Botanic Gardens include plant expedition, cultivation, research and development, utilization and dissemination of conservation activities. [42]. It has been carried out since at the beginning reconstruction of Bogor Botanic Garden. According to the herbarium specimen preserved in Bogor Botanic Gardens and catalogue database, C. micracantha was recorded as plant living collection in 1866 [43]. Information regarding the living collection of C.micracantha at the period of Teijsmann and the following periods is very limited. The plant living collections in Botanic Gardens are very constant change, some species may be die due to the age of plant living collections. Another may be fall and get physical damage due to pest, disease and environment fluctuation [44]. According to the plant living collection database, C. micracantha is recorded back in 2008 and 2019. The living collection of $C$. micracantha are collected from Sumbawa Island, Panua Nature Reserve (Gorontalo), and Bali. This plant living collection has been completely identified as Capparis sp. After entering the flowering phase, this plant has been completely identified as $C$. micracantha. The same situation also happened in Purwodadi Botanic Gardens in which plant living collections from Annonaceae family remained unidentified at the first time of collection. Those were then completely identified as certain species name based on their morphological appearances [45], [46]. Six plant living collections of C.micracantha are recorded, four of those have been entering flowering phase, and two individuals have been producing fruits. The study related to plants' reproductive 
biology is considered an important aspect in plant conservation. It provides many information for artificial breeding at botanic gardens [42]. The flower development, flowering phases, and fruiting periods are examples of the study tightly related to reproductive biology [47]-[49]. The period of flowering and fruiting this species has been observed throughout the year. In its natural habitat, it is known that this species is capable of flowering more than once a year [50]. This species has two type of flowers including complete flower and incomplete flower. The number of incomplete flowers is higher than the complete flowers, so the number of fruits that are formed in each season is only 0-4 (very rare). The development process from prospective fruit until ripe fruits requires around 3 month 10 days. The shape of fruit is round, the young fruit has green color and turn to red when the fruits ripe. The ripe fruit has a sweet taste and many seeds. The seeds are relatively small with kidney-like appearance. Multi propagation of this species has been conducted since several years ago in Botanic Gardens. The species has been multi propagated through the seeds. The seeds are germinated in small polybags or plastic pots. The germination process of this species is relatively simple and easy.
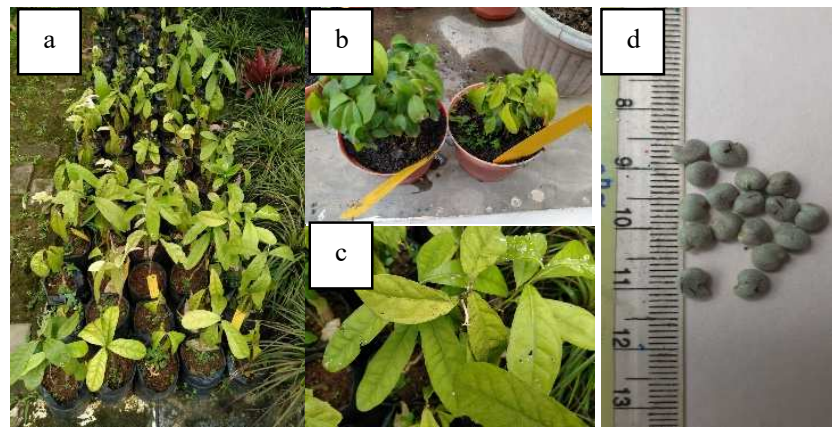

Fig. 6 Multi propagation of Capparis micracantha through the seeds: a). seedlings of $C$. micracantha, b). seedling grows in plastic pots, c). leaves of seedling, d). Seeds of C. micracantha

The ripe fruits of $C$. micracantha have red skin color. If the fruit opens, it will be seen white flesh wrapping many seeds. The flesh of fruits has sweet taste. The number of seeds per fruit are around $20-40$ seeds. The seed has a like kidney appearance, brown creamy color. The seeds have a size around $1-1.5 \mathrm{~mm}$ and $1 \mathrm{~mm}$ width. The seeds are relatively hard structure and can be able to germinate after storing during a week in plastic bag at room temperature. The seeds are produced in numerous numbers, whitish, slimy and sweet pulp. The seeds of $C$. micracantha are germinating well in sand growing media. After seven days planting the seeds in growing media, the seeds will germinate completely in the day of 15. The seeds are recalcitrant in which it is not be able to store in long period time. The type of germination is a hypogeal. The period required to grow from the first leaf to the second and subsequent leaves is very slow. The growth are also relatively slow when the seedlings are removed to the polybag. The plants are still small, with $20-35 \mathrm{~cm}$ high and 57 leaves after 3 years from its first germination. The problem of this species is related to the seedling growth. The seedlings are not growing well in multi propagation media. The seedlings take many years to grow to become mature individuals. The multi propagation of this species still remains a challenge.

\section{CONCLUSION}

SVM and GLM produce almost similar predictive distribution map of Capparis micracantha. The predictive maps of those models show some parts of Aceh, West Kalimantan, Moluccas, and Southern part of Papua are predicted as potential distribution areas of $C$. micracantha based on climatic variable and elevation as predictors of the model. The ex-situ conservation of $C$. micracantha has an obstacle in seedling growth. The growth rate of seedlings is relatively slow.

\section{ACKNOWLEDGMENT}

The authors are grateful to the Head of Botany Division, Research Center for Biology-Indonesian Institute of Sciences (LIPI), for allowing us to collect any information about C.micracantha from herbarium specimen collections. We are obliged to Harto and our colleagues who work in Pembibitan Building IX, in Vak II.Q and Vak XVII.

\section{REFERENCES}

[1] D. J. Mabberley, Mabberley's plant-book: a portable dictionaryof plants, their classification and uses. England: Cambridge University Press, 2008.

[2] M. Jacobs, "The genus Capparis (Capparaceae) from the Indus to the Pacific," Blumea - Biodiversity, Evol. Biogeogr. Plants, vol. 12, no. 3, pp. 385-541, 1964.

[3] D. T. Sy et al., "Capparis kbangensis (Capparaceae), a new species from central Vietnam,” PhytoKeys, vol. 151, pp. 83-91, 2020.

[4] M. A. R. Batuyong, M. A. Calaramo, and G. J. D. Alejandro, "A checklist and conservation status of vascular plants in the Limestone forest of Metropolitan Ilocos Norte Watershed Forest Reserve, Northwestern Luzon, Philippines," Biodiversitas, vol. 21, no. 9, pp. 3969-3981, 2020.

[5] M. Jacobs, "Capparidaceae," in Flora Malesiana, Series I Spermatophyta, Volume 6, C. G. G. J. van Steenis, Ed. Djakarta: Noordhoff-Kolff, 1960, pp. 61-105.

[6] W. Widodo and M. J. Luthfi, "Checklist of flowering plants (Magnoliophyta) of mount Nglanggeran, Gunungkidul: confirmation and update of Flora of Java and APG III," Biol. Med. Nat. Prod. Chem., vol. 6, no. 1, pp. 19-36, 2017.

[7] Y. W. N. Ratnaningrum, S. Indrioko, E. Faridah, and A. Syahbudin, "View of Gene flow and selection evidence of sandalwood (Santalum album) under various population structures in Gunung Sewu (Java, Indonesia), and its effects on genetic differentiation," Biodiversitas, vol. 18, no. 4, pp. 1493-1505, 2017.

[8] Y. W. N. Ratnaningrum and A. Kurniawan, "View of Floral structure and genetical differences of sandalwood variants in Gunung Sewu (Java, Indonesia), and its effects on breeding systems and reproductive ability," Biodiversitas, vol. 20, no. 2, pp. 393-404, 2019.

[9] J. B. Kim and D. H. Bae, "Intensification characteristics of hydroclimatic extremes in the Asian monsoon region under 1.5 and $2.0^{\circ} \mathrm{C}$ of global warming," Hydrol. Earth Syst. Sci., vol. 24, no. 12, pp. 5799-5820, Dec. 2020.

[10] G. U. Stuart, "Salimbagat / Capparis micracantha DC," List of Philipine herbal medicine plant, 2018. [Online]. Available: http://www.stuartxchange.com/Salimbagat. [Accessed: 25-May2021].

[11] O. Neamsuvan, P. Komonhiran, and K. Boonming, "Medicinal plants used for hypertension treatment by folk healers in Songkhla province, Thailand," J. Ethnopharmacol., vol. 214, pp. 58-70, Mar. 2018.

[12] F. I. Windardi, "Capparis micracantha DC," in Plant Resources of South-East Asia No 12 (2): Medicinal and poisonous plants 2, J. L. C. H. Van Valkenburg and N. Bunyapraphatsara, Eds. Netherlands: Backhuys Publisher, 2001, p. 140. 
[13] K. C. Chinsembu, "Diabetes mellitus and nature's pharmacy of putative antidiabetic plants," J. Herb. Med., vol. 15, p. 100230, Mar. 2019.

[14] P. Somwong and C. Chuchote, "Determination of Lupeol, a Cytotoxic Compound Against SW620 Cells in the Extracts of Ha-Rak Recipe," Pharmacogn. J., vol. 13, no. 1, pp. 133-141, 2021.

[15] J. Lohakul et al., "The protective effect of polyherbal formulation, Harak Formula, on UVA-induced photoaging of human dermal fibroblasts and mouse skin via promoting Nrf2-regulated antioxidant defense," Front. Pharmacol., vol. 12, p. 649820, Apr. 2021.

[16] C. N. Johnson et al., "Biodiversity losses and conservation responses in the Anthropocene," Science (80-. )., vol. 356, no. 6335, pp. 270 275, Apr. 2017

[17] W. J. Ripple, C. Wolf, T. M. Newsome, M. Hoffmann, A. J. Wirsing, and D. J. McCauley, "Extinction risk is most acute for the world's largest and smallest vertebrates," Proc. Natl. Acad. Sci. U. S. A., vol. 114, no. 40, pp. 10678-10683, Oct. 2017.

[18] A. Qin et al., "Maxent modeling for predicting impacts of climate change on the potential distribution of Thuja sutchuenensis Franch., an extremely endangered conifer from southwestern China," Glob. Ecol. Conserv., vol. 10, pp. 139-146, Apr. 2017.

[19] J. C. Deb, S. Phinn, N. Butt, and C. A. McAlpine, "The impact of climate change on the distribution of two threatened Dipterocarp trees," Ecol. Evol., vol. 7, no. 7, pp. 2238-2248, Apr. 2017.

[20] A. Norberg et al., "A comprehensive evaluation of predictive performance of 33 species distribution models at species and community levels," Ecol. Monogr., vol. 89, no. 3, p. 1370, Aug. 2019

[21] E. Kaky, V. Nolan, A. Alatawi, and F. Gilbert, "A comparison between Ensemble and MaxEnt species distribution modelling approaches for conservation: A case study with Egyptian medicinal plants," Ecol. Inform., vol. 60, p. 101150, Nov. 2020.

[22] M. Abdelaal, M. Fois, G. Fenu, and G. Bacchetta, "Using MaxEnt modeling to predict the potential distribution of the endemic plant Rosa arabica Crép. in Egypt," Ecol. Inform., vol. 50, pp. 68-75, Mar 2019.

[23] K. Zhang et al., "Impact of climate factors on future distributions of Paeonia ostii across China estimated by MaxEnt," Ecol. Inform., vol. 50, pp. 62-67, Mar. 2019.

[24] N. Xu, F. Meng, G. Zhou, Y. Li, B. Wang, and H. Lu, "Assessing the suitable cultivation areas for Scutellaria baicalensis in China using the Maxent model and multiple linear regression," Biochem. Syst. Ecol., vol. 90, p. 104052, Jun. 2020

[25] L. Marshall et al., "The interplay of climate and land use change affects the distribution of EU bumblebees," Glob. Chang. Biol., vol. 24, no. 1, pp. 101-116, Jan. 2018

[26] M. S. Hosseinzadeh, F. Q. Masood, N. Babak, R. Dennis, and S. M. Kazemi, "Habitat suitability and modelling the potential distribution of the Plateau Snake Skink Ophiomorus nuchalis (Sauria scincidae) on the Iranian Plateau," North. West. J. Zool., vol. 14, no. 1, pp. 6063, 2018.

[27] A. Yudaputra, I. P. Astuti, and W. P. Cropper, "Comparing six different species distribution models with several subsets of environmental variables: Predicting the potential current distribution of Guettarda speciosa in Indonesia," Biodiversitas J. Biol. Divers., vol. 20, no. 8, pp. 2321-2328, Jul. 2019

[28] A. Yudaputra, "Modelling potential current distribution and future dispersal of an invasive species Calliandra calothyrsus in Bali Island, Indonesia," Biodiversitas J. Biol. Divers., vol. 21, no. 2, pp. 674-682, Jan. 2020

[29] D. A. Pisner and D. M. Schnyer, "Support vector machine," in Machine Learning: Methods and Applications to Brain Disorders, Elsevier, 2019, pp. 101-121.

[30] J. M. Kass, S. I. Meenan, N. Tinoco, S. F. Burneo, and R. P. Anderson, "Improving area of occupancy estimates for parapatric species using distribution models and support vector machines," Ecol. Appl., vol. 31 , no. 1, p. e02228, Jan. 2021

[31] A. Yudaputra, I. Fijridiyanto, and W. P. Cropper, "The potential impact of climate change on the distribution pattern of Eusideroxylon zwageri (Bornean Ironwood) in Kalimantan, Indonesia," Biodiversitas, vol. 21 , no. 1 , pp. $326-333,2020$

[32] F. Ghareghan, G. Ghanbarian, H. R. Pourghasemi, and R. Safaeian, "Prediction of habitat suitability of Morina persica L. species using artificial intelligence techniques," Ecol. Indic., vol. 112, p. 106096, May 2020.

[33] O. Ovaskainen et al., "How to make more out of community data? A conceptual framework and its implementation as models and software," Ecol. Lett., vol. 20, no. 5, pp. 561-576, May 2017.

[34] F. K. C. Hui, "Boral: Bayesian ordination and regression analysis," $R$ package version 1.4, 2017. [Online]. Available: https://cran.rproject.org/package=boral. [Accessed: 25-May-2021].

[35] A. Gayen and H. R. Pourghasemi, "Spatial modeling of gully erosion: A new ensemble of CART and GLM data-mining algorithms," in Spatial Modeling in GIS and R for Earth and Environmental Sciences, Elsevier, 2019, pp. 653-669.

[36] T. Connor et al., "Effects of grain size and niche breadth on species distribution modeling," Ecography (Cop.)., vol. 41, no. 8, pp. 12701282, Aug. 2018.

[37] T. H. Booth, H. A. Nix, J. R. Busby, and M. F. Hutchinson, "Bioclim: The first species distribution modelling package, its early applications and relevance to most current MaxEnt studies," Divers. Distrib., vol 20, no. 1, pp. 1-9, Jan. 2014.

[38] S. E. Fick and R. J. Hijmans, "WorldClim 2: new 1-km spatial resolution climate surfaces for global land areas," Int. J. Climatol., vol. 37, no. 12, pp. 4302-4315, Oct. 2017.

[39] R. J. Hijmans, S. Phillips, J. Leathwick, and J. Elith, "Dismo: Species distribution modeling," $R$ Package Version 1.3-3., 2020. [Online]. Available: https://cran.r-project.org/web/packages/dismo/index.html. [Accessed: 24-May-2021]

[40] J. C. Cooper and J. Soberón, "Creating individual accessible area hypotheses improves stacked species distribution model performance," Glob. Ecol. Biogeogr., vol. 27, no. 1, pp. 156-165, Jan. 2018.

[41] W. J. Krzanowski and D. J. Hand, ROC: Curves for continuous data Boca Raton, FL: Chapman and Hall/CRC, 2009.

[42] T. Handayani, "Diversity, potential and conservation of Annonaceae in Bogor Botanic Gardens, Indonesia," Biodiversitas, vol. 19, no. 2, pp. 591-603, 2018

[43] J. E. Teysmann, Catalogus plantarum quae in Horto Botanico Bogoriensi coluntur. Batavia: Lands-Drukkerij, 1866.

[44] D. Setyanti and D. O. Pribadi, "Mapping the dynamics of dead trees collection to support sustainable landscape management at Bogor Botanic Gardens," in IOP Conference Series: Earth and Environmental Science, 2020, pp. 1-6.

[45] D. A. Lestari, R. Azrianingsih, and H. Hendrian, "Taxonomical position of Annonaceae species from East Java, Indonesia: Collections of Purwodadi botanic garden based on morphological character," Biodiversitas, vol. 18, no. 3, pp. 1067-1076, Jul. 2017.

[46] D. A. Lestari, A. P. Fiqa, and I. K. Abywijaya, "Leaf morphological traits of Orophea spp. (Annonaceae): Living collections of Purwodadi Botanic Gardens, East Java, Indonesia," Biodiversitas J. Biol. Divers., vol. 22, no. 6, pp. 3403-3411, Jun. 2021.

[47] T. Handayani, Yuzammi, and J. T. Hadiah, "Inflorescence morphology and development of Suweg (Amorphophallus paeoniifolius (Dennst.) Nicolson,” Biodiversitas, vol. 21, no. 12, pp. 5835-5844, Dec. 2020.

[48] F. Damayanti, R. Vitri Garvita, H. Wawangningrum, and S. Rahayu, "Flower development, pollen viability and pollen storage test of Aeschynanthus radicans," Biodiversitas, vol. 22, no. 4, pp. 1940-1945, Apr. 2021.

[49] D. A. Lestari and A. P. Fiqa, "Environmental factors influence on flowering and fruiting period of selected essential oil plants from annonaceae," Biodiversitas, vol. 21, no. 3, pp. 910-921, Mar. 2020.

[50] B. Moungsrimuangdee, P. Waiboonya, P. Larpkern, P. Yodsa-Nga, and M. Saeyang, "Reproductive phenology and growth of riparian species along Phra Prong river, Sa Kaeo province, Eastern Thailand," J. Landsc. Ecol., vol. 10, no. 2, pp. 35-48, 2017. 